\title{
Structural behaviour of square RC columns confined with CFRP wraps
}

\author{
A. Benredjem ${ }^{1}$, N. Chikh ${ }^{2}$, H.A. Mesbah ${ }^{3}$ and R. Benzaid ${ }^{4}$ \\ ${ }^{1,2}$ University of Mentouri Constantine, LMDC - Department of Civil Engineering, Constantine, Algeria \\ ${ }^{3}$ University of Rennes 1, L.G.C.G.M - Department of Civil Engineering, Rennes, France \\ ${ }^{4}$ University of Jijel, LGG - Department of Geology, Jijel, Algeria
}

\begin{abstract}
Loading capacity and strains of square reinforced concrete (RC) columns, strengthened with external carbon fiber reinforced polymer (CFRP) sheets, were tested and evaluated. The experimental parameters include: number of wrap layers, concrete strength and the slenderness of the columns (L/a). All test specimens were loaded to failure in axial compression. Compressive stress, axial and hoop strains have been recorded to evaluate the stress-strain relationship, ultimate strength, stiffness, and ductility of the specimens. Results clearly demonstrate that composite wrapping can enhance the structural performance of RC columns in terms of both maximum strength and ductility. The effects of test parameters are evidenced and compared.
\end{abstract}

\section{Introduction}

An increasing number of reinforced concrete structures have reached the end of their service life, either due to deterioration of the concrete and reinforcements caused by environmental factors, or due to an increase in applied loads. These deteriorated structures may be structurally deficient or functionally obsolete, and most are now in serious need of extensive rehabilitation. Carbon fiber reinforced plastics sheets or plates are well suited to this application because of their high strength-to-weight ratio, good fatigue properties, and excellent resistance to corrosion. Their application in civil engineering structures has been growing rapidly in recent years, and is becoming an effective and promising solution for strengthening deteriorated concrete members. Because CFRPs are quickly and easily applied, their use minimizes labour costs and can lead to significant savings in the overall costs of a project.

During the last decade, the use of FRP composites has been successfully promoted for external confinement of reinforced concrete (RC) columns all over the world. Several studies on the performance of FRP wrapped columns have been conducted, using both experimental and analytical approaches [1-9]. Such strengthening technique has proved to be very effective in enhancing their ductility and axial load capacity. However, most of the available studies on the behavior of FRP confined concrete columns have concentrated on circular shaped columns with normal strength. The data available for columns of square or rectangular cross sections have increased over recent years but are still limited [10-14]. Also the validation of these results and their applicability to large-scale RC columns is of great practical interest.
This field remains in its infancy stages and more research investigation is needed on this subject to study the effect of slenderness and that of concrete strength.

This study deals with a series of tests on square plain concrete (PC) and reinforced concrete (RC) columns strengthened with CFRP sheets. A total of 48 concrete specimens were tested under axial compression. The data recorded included the compressive loads, axial strains, and radial strains. The parameters considered are the number of composite layers ( 1 and 3 ), the compressive strength of the unconfined concrete $(25 \mathrm{MPa}$ and $60 \mathrm{MPa})$ and the columns' slenderness ratio L/a (2; 4 and 7.4). To comply with existing $\mathrm{RC}$ members in practice, where reduced cover is often present, the corners for all prismatic specimens were almost kept sharp for CFRP application.

\section{Experimental program}

\subsection{Materials}

The Two kind of concrete mix have been realised to investigate the influence of concrete strength, normal strength concrete (NSC- $25 \mathrm{MPa}$ ) and high strength concrete (HSC- $60 \mathrm{MPa}$ ). The carbon-fiber sheets used were the SikaWrap-230C product, a unidirectional wrap. The manufacturer's guaranteed tensile strength for this CFRP is $4300 \mathrm{MPa}$, with a tensile modulus of $238 \mathrm{GPa}$, an ultimate elongation of $1.8 \%$ and a fiber thickness of $0.13 \mathrm{~mm}$. The Sikadur-330 epoxy resin was used to bond the carbon fabrics over the square columns.

Table 1 summarizes the specimens involved in the experimental program. Eight series of experiments were 
performed to investigate the behavior of $\mathrm{PC}$ and $\mathrm{RC}$ square columns confined by CFRP composite. For all RC specimens the diameter of longitudinal and transverse reinforcing steel bars were respectively $12 \mathrm{~mm}$ and 8 $\mathrm{mm}$. The longitudinal steel ratio was constant for all specimens and equal to $2.25 \%$. The yield strength of the longitudinal and transversal reinforcement was $500 \mathrm{MPa}$ and $235 \mathrm{MPa}$; respectively. The specimen notations are as follows. The specimen notations are as follows. The first two letters refer to the type of concrete: PC for plain concrete and $\mathrm{RC}$ for reinforced concrete, followed by the concrete mixture: I for normal strength $(24.77 \mathrm{MPa})$ and II for high strength $(59.53 \mathrm{MPa})$. The next letter indicates the slenderness ratio: $x$ for $L / a=2, y$ for $L / a=4$ and $z$ for $\mathrm{L} / \mathrm{a}=7.14$. The last number specifies the number of layers.

Table 1. Details of test specimens

\begin{tabular}{|c|c|c|c|c|c|}
\hline $\begin{array}{l}\text { Specimen } \\
\text { designation }\end{array}$ & $\begin{array}{l}\text { Concrete } \\
\text { mixture }\end{array}$ & $\begin{array}{c}\text { Nominal dimensions } \\
(\text { side } \mathrm{x} \text { side } \mathrm{x} \\
\text { height }) \quad[\mathrm{mm}]\end{array}$ & $\begin{array}{l}\text { Number of } \\
\text { layers }\end{array}$ & $\begin{array}{l}\text { Unconfined concrete } \\
\text { strength }[\mathrm{MPa}]\end{array}$ & $\begin{array}{l}\text { Number of } \\
\text { specimens }\end{array}$ \\
\hline PCI. $\mathrm{x} 0$ & \multirow{12}{*}{ I } & 140x140x280 & - & \multirow{12}{*}{24.77} & 2 \\
\hline PCI. x1 & & $140 \times 140 \times 280$ & 1 & & 2 \\
\hline PCI. x3 & & $140 \times 140 \times 280$ & 3 & & 2 \\
\hline RCI. x0 & & $140 \times 140 \times 280$ & - & & 2 \\
\hline RCI. $x 1$ & & $140 \times 140 \times 280$ & 1 & & 2 \\
\hline RCI. x3 & & $140 \times 140 \times 280$ & 3 & & 2 \\
\hline RCI. y0 & & $140 \times 140 \times 560$ & - & & 2 \\
\hline RCI. y1 & & $140 \times 140 \times 560$ & 1 & & 2 \\
\hline RCI. y3 & & $140 \times 140 \times 560$ & 3 & & 2 \\
\hline RCI. z0 & & $140 \times 140 \times 1000$ & - & & 2 \\
\hline RCI. z1 & & $140 \times 140 \times 1000$ & 1 & & 2 \\
\hline RCI. z3 & & $140 \times 140 \times 1000$ & 3 & & 2 \\
\hline PCII. x0 & \multirow{12}{*}{ II } & $140 \times 140 \times 280$ & - & \multirow{12}{*}{59.53} & 2 \\
\hline PCII. x1 & & 140x140x280 & 1 & & 2 \\
\hline PCII. $x 3$ & & $140 \times 140 \times 280$ & 3 & & 2 \\
\hline RCII. $\mathrm{x} 0$ & & $140 \times 140 \times 280$ & - & & 2 \\
\hline RCII. x1 & & $140 \times 140 \times 280$ & 1 & & 2 \\
\hline RCII. x3 & & $140 \times 140 \times 280$ & 3 & & 2 \\
\hline RCII. y0 & & $140 \times 140 \times 560$ & - & & 2 \\
\hline RCII. y1 & & $140 \times 140 \times 560$ & 1 & & 2 \\
\hline RCII. y3 & & $140 \times 140 \times 560$ & 3 & & 2 \\
\hline RCII. z0 & & $140 \times 140 \times 1000$ & - & & 2 \\
\hline RCII. z1 & & $140 \times 140 \times 1000$ & 1 & & 2 \\
\hline RCII. z3 & & $140 \times 140 \times 1000$ & 3 & & 2 \\
\hline
\end{tabular}

\subsection{Specimen preparation}

After concrete columns were fully cured, FRP wrapping procedure was performed according to the procedure specified by the manufacturer. The CFRP jackets were applied to the specimens by manual wet lay-up process. The concrete specimens were cleaned and completely dried before the resin was applied. The epoxy resin was directly applied onto the substrate. The fabric was carefully placed into the resin with gloved hands and smooth out any irregularities or air pockets using a plastic laminating roller. The roller was continuously used until the resin was reflected on the surface of the fabric, an indication of fully wetting. A second layer of resin was applied to allow the impregnation of the CFRP. The following layer is applied in the same way. Finally, a layer of resin was applied to complete the operation. Each layer was wrapped around the column with an overlap of $1 / 4$ of the perimeter to avoid sliding or deboning of fibers during tests. The wrapped specimens were left at room temperature for 1 week before testing.

\subsection{Test procedures}

Specimens were loaded under a monotonic uni-axial compression load up to failure. The load was applied at a rate corresponding to $0.24 \mathrm{MPa} / \mathrm{s}$ and was recorded with an automatic data acquisition system. Axial and lateral strains were measured using appreciable extensometer. The instrumentation included one lateral linear variable differential transducer (LVDT) placed in the form of a square frame at the mid-height of the specimens. Measurement devices also included three vertical LVDTs to measure the average axial strains. Prior to testing, all CFRP-wrapped columns were capped with sulfur mortar at both ends.

\section{Test results and discussion}

Figures Compression behavior of the CFRP wrapped specimens was mostly similar in each series in terms of stress-strain curves and failure modes of the specimens. All confined concrete columns failed by fracture of the 
composite wrap at one of the corners, because of the high stress concentration at these locations, Figure. 1. The collapse occurred in a sudden and explosive way, though some popping noises were heard during various stages of loading and were attributed to microcracking of the concrete. The strain values observed for the jacket tensile failure were substantially lower than the FRP failure strain, as many authors have already published. For short specimens $(\mathrm{L} / \mathrm{a}=2)$, the fiber rupture starts mainly in their central zone, then propagates towards both ends. Regarding slender specimens, the collapse was mostly concentrated in their end regions, indicating that the greater the slender ratio, the smaller the area of CFRP ruptured.

For these columns at ultimate load, when confinement action was no longer provided due to FRP fracture, the internal steel started buckling and the crushed concrete fell down between the fractured FRP. Hence, this indicates that the concrete core is significantly damaged (but yet confined) even before reaching ultimate load. For all confined specimens, delamination was not observed at the overlap location of the jacket, which confirmed the adequate stress transfer over the splice.
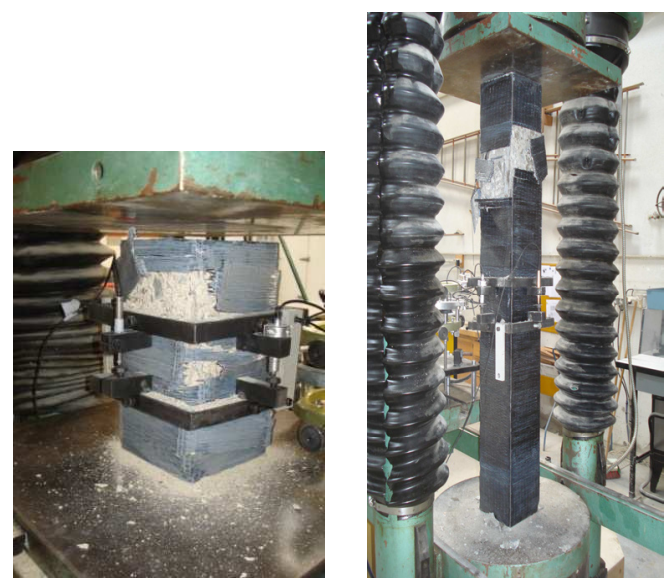

Fig. 1. Failure of CFRP confined specimens

The average experimental results are reported in Table 2, with the increase in terms of compressive strength $\left(\mathrm{f}^{\prime}{ }_{\mathrm{cc}} / \mathrm{f}_{\mathrm{co}}\right)$ and ductility $\left(\varepsilon_{\mathrm{cc}} / \varepsilon_{\mathrm{co}}\right)$, intended as ultimate axial displacement.

Table 2. Test results

\begin{tabular}{|c|c|c|c|c|c|c|c|}
\hline $\begin{array}{c}\text { Specimen } \\
\text { designation }\end{array}$ & $\begin{array}{c}\mathrm{f}_{\text {co }}[\mathrm{MPa}] \\
{\left[\begin{array}{c}\mathrm{f}_{\mathrm{cc}}^{\prime} \\
{[\mathrm{MPa}]}\end{array}\right.}\end{array} \mathrm{f}_{\mathrm{cc}} / \mathrm{f}_{\mathrm{co}}$ & $\begin{array}{c}\varepsilon_{\mathrm{cc}} \\
{[\% \text { ] }}\end{array}$ & $\varepsilon_{\mathrm{cc}} / \varepsilon_{\mathrm{co}}$ & $\begin{array}{c}\varepsilon_{\mathrm{h}, \mathrm{rup}} \\
{[\%]}\end{array}$ & $\varepsilon_{\mathrm{h}, \mathrm{rup}} / \varepsilon_{\mathrm{ho}}$ \\
\hline PCI. x0 & 24.77 & 24.77 & 1.00 & 2.20 & 1.00 & 3.88 & 1.00 \\
\hline PCI. x1 & & 27.66 & 1.11 & 6.58 & 2.99 & 24.33 & 6.27 \\
\hline PCI. x3 & & 32.03 & 1.29 & 5.89 & 2.67 & 17.01 & 4.38 \\
\hline RCI. x0 & 33,59 & 33.59 & 1.00 & 7.61 & 1.00 & 17.00 & 1.00 \\
\hline RCI. x1 & & 39.52 & 1.17 & 15.06 & 1.97 & 20.58 & 1.21 \\
\hline RCI. x3 & & 49.12 & 1.46 & 15.66 & 2.05 & 25.50 & 1.50 \\
\hline RCI. y0 & 30.49 & 30.49 & 1.00 & 1.67 & 1.00 & 9.78 & 1.00 \\
\hline RCI. y1 & & 36.73 & 1.20 & 3.02 & 1.80 & 8.69 & 0.88 \\
\hline RCI. y3 & & 41.85 & 1.37 & 5.61 & 3.35 & 7.77 & 0.79 \\
\hline RCI. z0 & 24.69 & 24.69 & 1.00 & 0.96 & 1.00 & - & - \\
\hline RCI. z1 & & 33.92 & 1.37 & 2.05 & 2.13 & - & - \\
\hline RCI. z3 & & 39.17 & 1.58 & 3.64 & 3.79 & - & - \\
\hline PCII. x0 & 59.53 & 59.53 & 1.00 & 3.66 & 1.00 & 3.31 & 1.00 \\
\hline PCII. x1 & & 61.30 & 1.02 & 2.46 & 0.67 & 5.43 & 1.64 \\
\hline PCII. x3 & & 70.35 & 1.18 & 3.09 & 0.84 & 13.39 & 4.04 \\
\hline RCII. x0 & 63.79 & 63.79 & 1.00 & 3.05 & 1.00 & 10.30 & 1.00 \\
\hline RCII. x1 & & 74.84 & 1.17 & 3.87 & 1.26 & 16.36 & 1.58 \\
\hline RCII. x3 & & 79.59 & 1.24 & 5.29 & 1.73 & 7.96 & 0.77 \\
\hline RCII. y0 & 63.62 & 63.62 & 1.00 & 2.05 & 1.00 & 0.35 & 1.00 \\
\hline RCII. y1 & & 80.78 & 1.26 & 2.82 & 1.37 & 0.76 & 2.17 \\
\hline RCII. y3 & & 82.44 & 1.29 & 2.79 & 1.36 & 0.76 & 2.17 \\
\hline RCII. z0 & 69.98 & 69.98 & 1.00 & 2.08 & 1.00 & 0.49 & 1.00 \\
\hline RCII. z1 & & 75.77 & 1.08 & 2.53 & 1.21 & 0.82 & 1.67 \\
\hline RCII. z3 & & 81.51 & 1.16 & 2.70 & 1.29 & 1.36 & 2.77 \\
\hline
\end{tabular}

Representative stress-strain curves for each series of tested CFRP-wrapped specimens are reported in figure 2 (a-c) for NSC and in figure 3 (a-c) for HSC. They give the axial stress versus the axial and lateral strains for specimens with zero, 1 and 3 layers of CFRP wrap considering various slenderness ratio L/a (2, 4 and 7.14). 


\subsection{Stress-Strain Response}

For NSC, all CFRP strengthened specimens showed a typical bilinear trend with a transition zone. Three zones can be observed for the stress-strain curves of the CFRPconfined specimens. The first zone is essentially a linear response governed by the stiffness of the unconfined concrete, which indicates that no confinement is activated in the CFRP wraps since the lateral strains in the concrete are very small. The unconfined concrete specimens show a sudden drop in stiffness and strength after reaching the maximum load point. In the second zone, a nonlinear transition occurs as the concrete expands, thus producing larger lateral strains. The CFRP wrap reacts accordingly and a confining action is created on the concrete core. During this stage a loss of stiffness occurs due to the rapidly growing network of cracks in the concrete. Finally, in the third zone, the concrete is fully cracked and the CFRP confinement is activated to provide additional load carrying capacity by keeping the concrete core intact. The stress-strain curve here increases linearly up to failure. However, no distinct post behaviour is observed for specimens with higher slenderness ratio. On overall, both ultimate compressive strength and ultimate strain are variably enhanced depending on the number of layers and the slenderness ratio.

As for the previous case of NSC, the first slope of the curve, regarding specimens with HSC, is also not substantially altered by the presence of CFRP. In this initial elastic zone, the confined and the unconfined specimens behave in the same manner, irrespective of the number of layers. The strengthening effect of the CFRP layers begins only after the concrete has reached the peak strength of the unconfined concrete: transversal strains in the concrete activate the CFRP jacket. The increase of load would produce large lateral expansions, and consequently a higher confining pressure, provided that the number of composite layers is quite sufficient. With low levels of confinement (one CFRP layer), the second part of the bilinear curve shifts from strain hardening to a flat plateau with a drastically reduced ductility.

No distinct post behaviour is observed as the slenderness ratio increases and little improvement is achieved in both strength and ductility.

\subsection{Effect of unconfined concrete strength}

To investigate the effects of concrete quality, different concrete strength (24.77 $\mathrm{MPa}$ and $59.35 \mathrm{MPa}$ ) have been used. Considering specimens confined with 3 CFRP layers, it can be seen from stress strain curves in figures 2 and 3 a varying strength increase of 37 to $58 \%$ for NSC specimens and of 16 to $29 \%$ for HSC specimens. This effect is even more pronounced on the axial deformations, where the relative variation increases are of 105 to $280 \%$ for NSC specimens and 25 to $73 \%$ for HSC specimens. This clearly indicates that the effect on the strength and ductility capacities decreases with increasing concrete strength, as found by other authors. Mechanical effects of different concrete quality are also evident in the first branch of the curves, where stronger concrete shows higher stiffness with respect to concrete with lower strength.

\subsection{Effect of CFRP Strengthening Ratio}

In all cases the increase of the numbers of sheets generated an increase of compressive strength as well as axial deformation capacity. The level of increase is important for NSC specimens. Considering the cases of 1 and 3 CFRP layers, from results displayed in Table 2 and figure 2 , it can be evaluated that the increase in the bearing capacity varies roughly from $17 \%$ to $58 \%$ as compared to the relative unconfined specimens, while the ultimate vertical deformations increase on average from $80 \%$ to $280 \%$. From these findings, it is possible to assert that the increase in the number of CFRP sheets has a significant influence even though the increase in terms of strength is not as important as that of axial deformations which increase almost proportionally to the FRP strengthening ratio.

The effect of the number of CFRP layers on HSC specimens is relatively moderate compared to the case discussed previously. In this situation, the confinement pressure is activated at higher load (around $80 \%$ of the ultimate value). Consequently, the enhancement in the load carrying capacity is reduced and varies roughly from $8 \%$ to $29 \%$, whereas the ultimate axial deformations undergo a significant reduction displaying an increase on average from 21 to $125 \%$, as illustrated in Table 2 and in figure 3. It should be emphasized that the presence of quite sharp corners in all tested CFRP jacketed columns produced a cutting effect on confining sheets and hence affected the rate of enhancement in their load carrying and deformation capacities.

\subsection{Effect of slenderness ratio}

The comparison of results recorded for a slenderness ratio varying from 2 to 7.14 shows for NSC wrapped RC specimens a moderate decrease in the load carrying capacity and an important reduction in the axial deformation. However, in the case of HSC jacketed specimens, the strength was almost not affected whereas the ductility underwent a moderate decrease. This may be explained by the late activation of the confinement pressure which occurred at higher load (around $80 \%$ of the ultimate value).

On overall, the efficiency of the confinement provided by composite wraps was greatly affected by the premature damage of the CFRP fabric at the sharp column corner.

\section{Conclusions}

An experimental study on the axial compression behaviour of square RC columns confined externally with CFRP was presented. The following conclusions can be drawn: 
- The failure of all CFRP wrapped specimens occurred in a sudden and explosive way preceded by typical creeping sounds. For short specimens $(\mathrm{L} / \mathrm{a}=2)$, the fiber rupture 


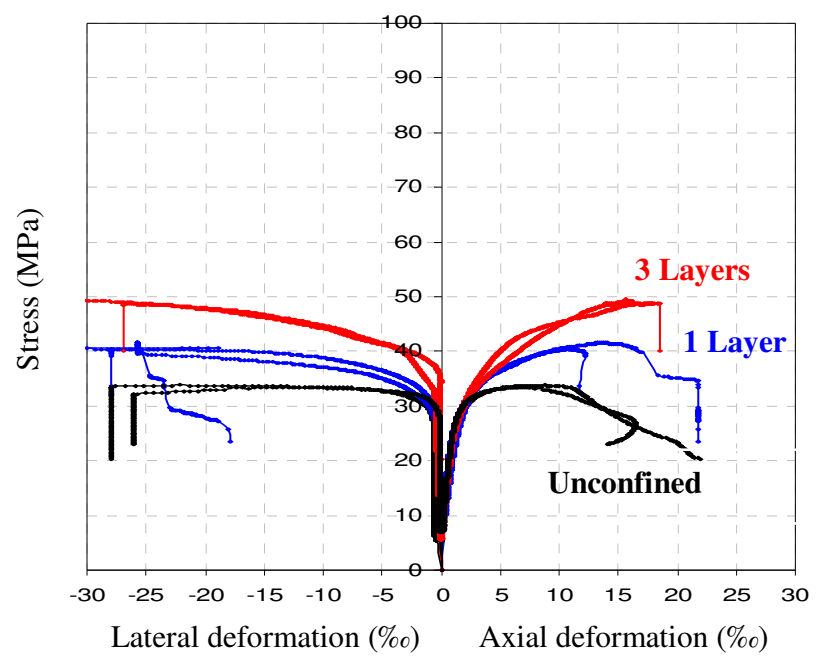

(a) RCI.x series

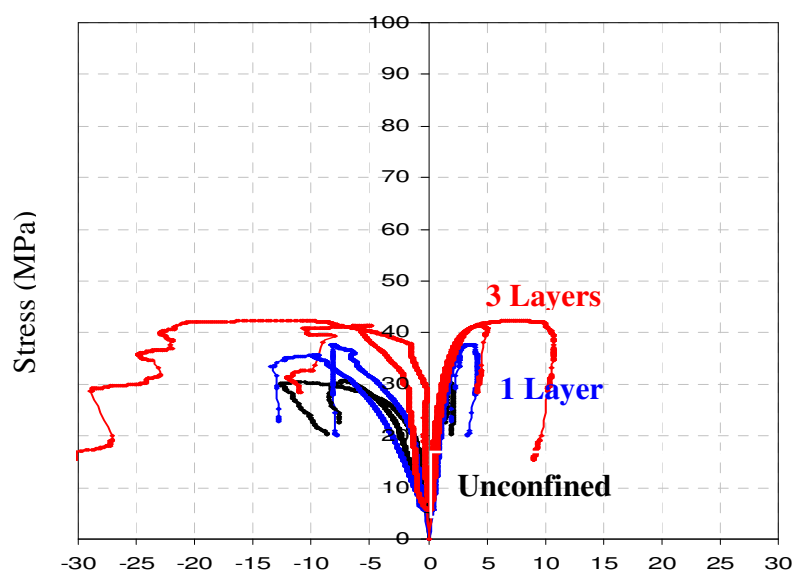

Lateral deformation (\%o)

Axial deformation (\%o)

(b) RCI.y series

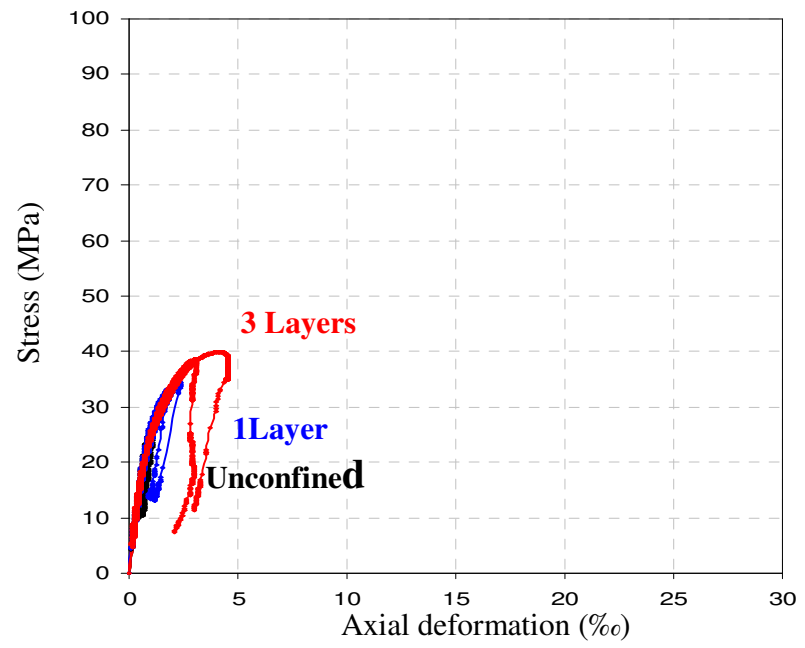

(c) RCI.z series

Fig. 2. Stress strain curves of NSC CFRP specimens

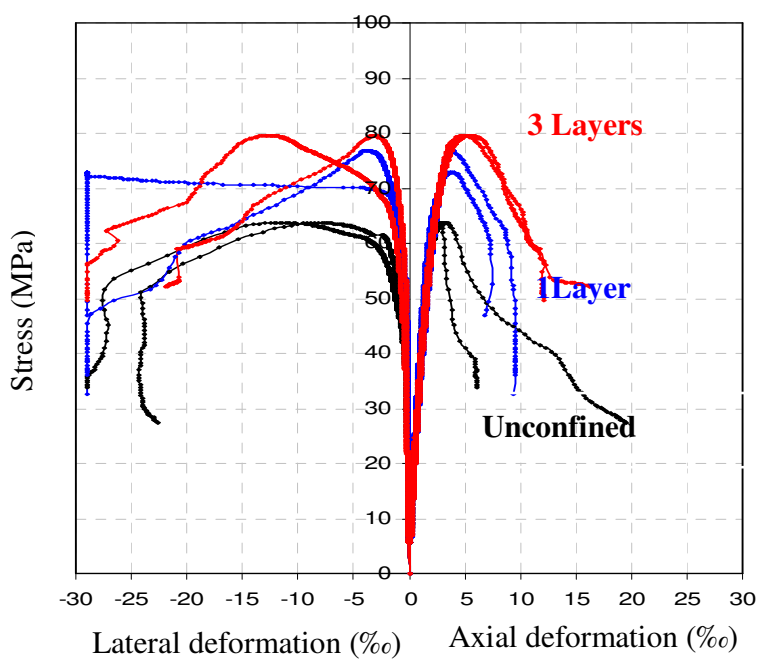

(a) RCII.x series

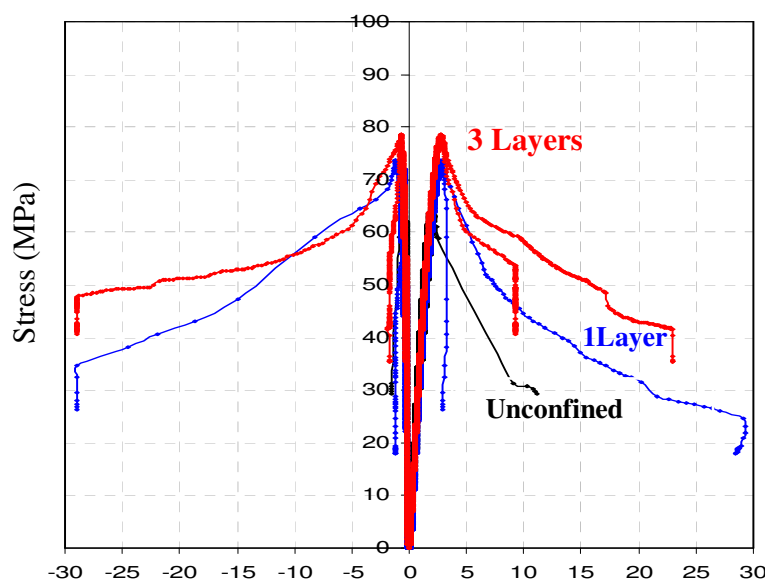

Lateral deformation (\%o) Axial deformation (\%o)

(b) RCII.y series

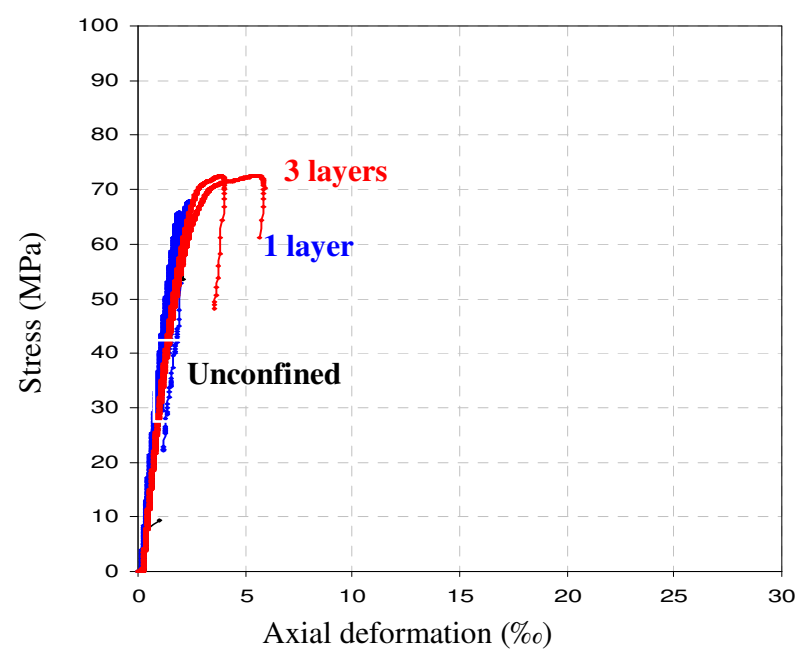

(c) RCII.z series

Fig.3. Stress strain curves of HSC FRP specimens 
starts mainly in their central zone, then propagates towards both ends. Regarding slender specimens, the collapse was mostly concentrated in their upper or lower regions.

- Increasing the amount of CFRP sheets produce an increase in the compressive strength of the confined column but with a rate lower compared to that of the deformation capacity which almost proportional to the CFRP strengthening ratio;

- The CFRP confinement on low-strength concrete specimens produced higher results in terms of strength and strains than for high-strength concrete similar specimens. Therefore, the effect of CFRP confinement on the bearing and deformation capacities decreases with increasing concrete strength;

- The effect of increasing the slenderness ratio results in a decrease of the strengthening effect on strength and ductility. The rate of decrease is more important for NSC specimens.

\section{References}

1. H. Saadatmanesh, M.R. Ehsani, W. Li, ACI Stru. J., 91, 4, (1994)

2. A. Nanni, N.M. Bradford, Constr. Build. Materials, 9, 2, (1995)

3. R V.M. Karbhari, Y. Gao, ASCE J. Mat. Civ. Eng., 9, 4, (1997)

4. P. Rochette, P. Labossière, ASCE J. Comp. Constr., 4, 3, (2000)

5. O. Chaallal, M. Hassen, M. Shahawy, ACI Stru. J., 100, 2, (2003)

6. J.L. Pan, T. Xu, Z.J. Hu, Constr. Build. Materials, 21, 1, (2007).

7. A. Chakrabarti, A.M. Chandra, P. Bharagava, ASCE J. Reinf. Plas. Comp., 27, 12, (2008)

8. C. Pellegrino, C. Modena, ASCE J. Comp. Constr., 14, 6, (2010)

9. J. Piekarczyk, W. Piekarczyk, S. Blazewicz, Constr. Build. Materials, 25, 5, (2011)

10. Y.A. Al-Salloum, J. Comp. Part B, 38, 5-6, (2007)

11. H. Toutanji, M. Han, J. Gilbert, S. Matthys, ASCE J. Comp. Constr., 14, 1, (2010)

12. T. Turgay, Z. Polat, H. O. Koksal, B. Doran, C. Karakoc, Mat. Design, 31, 1, (2010)

13. A. De Luca, A. Nanni, ASCE J. Comp. Constr., 15, 3, (2011)

14. Z. Wang, D. Wang, S.T. Smith, D. Lu, ASCE J. Comp. Constr., 16, 2, (2012) 